\title{
Evaluation of a radioactive rRNA:cDNA- hybridisation assay for the direct detection of Chlamydia trachomatis in urogenital specimens
}

\author{
H NÄHER,* B NIEBAUER, $\dagger$ M HARTMANN,* J SÖLTZ-SZÖTS, $\dagger$ D PETZOLDT* \\ From the Department of Dermatology and Venereology, Ruprecht-Karls-University, Heidelberg, ${ }^{*}$ Federal \\ Republic of Germany and Ludwig Boltzmann Institute for Research of Infectious Venereo-Dermatological \\ Disease, Wien, $†$ Austria
}

SUMMARY A radioactive cDNA probe complementary to chlamydial ribosomal RNA was used to detect $C$ trachomatis in urogenital specimens. Of 37 specimens positive with cell culture 31 were confirmed by the rRNA:cDNA hybridisation test, the sensitivity being $83.8 \%$. The specificity of the hybridisation test was $94.4 \%$, as 186 of 197 specimens that were negative by cell culture were also negative when assessed by the hybridisation method. Given a prevalence of $15.8 \%$ the predictive values for positive and negative results were $73.8 \%$ and $96.9 \%$, respectively. In additional experiments the possible role of microorganisms added to the specimen collection medium was investigated. However, no indication for crosshybridisation was found; at high concentrations microorganisms interfered with the test procedure.

Chlamydia trachomatis is the most common agent of sexually transmitted diseases in western countries. ${ }^{2}$ The mild and often asymptomatic course of urogenital chlamydia infection requires the microbiological investigation of patients and even the screening of risk populations for an effective epidemiological control.

The routine detection of $C$ trachomatis cannot yet be considered adequate. Indeed the isolation in cell culture is the method of choice but the performance of cell culture is limited owing to the cost, the requirement of specialised facilities and restricted transportation of specimens because of a low viability of chlamydia. ${ }^{36}$ An improvement with respect to these limitations was the introduction of antigen detection tests using specific antibody either with immunofluorescence $^{48}$ or in enzyme-immunoassays. ${ }^{7910}$ However, these tests cannot fully satisfy the requirements either. Especially in populations with low prevalence of chlamydial infections the sensitivity of antigen detection tests turned out to be relatively low. ${ }^{11}$

A new approach to this issue is DNA-hybridisation technique ${ }^{1213}$ which has so far not yet been sufficiently

Address for reprints: Dr $\mathrm{H}$ Näher, Department of Dermatology and Venereology, Ruprecht-Karls-Universität, Voß-Str.2, 6900 Heidelberg 1, Federal Republic of Germany.

Accepted for publication 26 June 1989 evaluated. In particular the different technical variations of this method regarding the kind of nucleic acid probes used, the mode of hybridisation and the type of the visualisation system need further investigation before a final estimation of the relevance of hybridisation technology for routine diagnosis of $C$ trachomatis can be given. In this study a hybridisation assay that allows the detection of $C$ trachomatis ribosomal RNA (rRNA) in the soluble phase of the transport medium by a radio-labelled complementary DNA-probe was evaluated. In addition the possible role of microorganisms present in the urogenital tract to interfere with the test procedure has been investigated.

\section{Patients, materials and methods}

\section{STUDY POPULATION}

Urogenital specimens were collected from 105 men and 129 women attending sexually transmitted diseases (STD) outpatient clinics in Heidelberg and Wien.

\section{SPECIMEN COLLECTION}

Urethral specimens were collected 4 hours after micturition by inserting a swab $2-4 \mathrm{~cm}$ into the urethra and withdrawing it after rotating. Endocervical specimens were obtained after removal of the cervical mucus by inserting a swab into the cervical canal, rotating it several times and withdrawing it. Sampling 
for the hybridisation test was carried out with swabs and transport medium provided in a specimen collection kit (Gen-Probe, Inc., San Diego). For cell culture ENT swabs (Mast Diagnostics) were used and placed in saccharose/phosphate transport medium.

ISOLATION OF C TRACHOMATIS IN CELL CULTURE McCoy cells were cultured on glass coverslips in Roswell Park Memorial Institute (RPMI) medium 1640 supplemented with $10 \%$ fetal calf serum. After growth to monolayers, cell cultures were treated with cycloheximide at a final concentration of $1 \mu \mathrm{g} / \mathrm{ml}$. Cultures were then inoculated with $0.2 \mathrm{ml}$ transport medium, centrifuged at $3000 \mathrm{~g}$ for one hour, medium changed after two hours, and then incubated for up to 72 hours. To detect inclusions cells were fixed in methanol for $10 \mathrm{~min}$ and $20 \mu \mathrm{l}$ of fluorescein conjugated monoclonal antibody (Syva-Merck, Darmstadt) applied. After being incubated in a moist chamber for $15 \mathrm{~min}$ at $37^{\circ} \mathrm{C}$ coverslips were rinsed with distilled water, air dried, mounted and examined with a Zeiss fluorescence microscope. In the cases in which a passage was performed cells of the first culture were scraped from the coverslips, carried over to a fresh monolayer for inoculation and then processed like the primary cultures.

\section{DETECTION OF C TRACHOMATIS BY RRNA:CDNA HYBRIDISATION}

The transport medium contains substances to release rRNA from microorganisms. Transport medium (50 $\mu$ l) was transferred to a tube and $100 \mu l^{125}$ I-labelled DNA probe (Gen-Probe, Inc., San Diego) complementary to $C$ trachomatis rRNA were added. The tubes were then placed in a waterbath and incubated for 2 hours at $60^{\circ} \mathrm{C}$ to form stable rRNA:cDNA hybrids. Afterwards $2 \mathrm{ml}$ separation reagent containing buffer and magnetic particles was added to the tubes and incubation continued at $60^{\circ} \mathrm{C}$ for $5 \mathrm{~min}$ to allow magnetic particles to bind double-stranded rRNA:cDNA hybrids. Next, the tubes were placed on a magnetic separation base (Gen-Probe, Inc., San Diego) resulting in separation of magnetic particle bound hybrids from the remaining non-hybridised probes and after 2 min of holding the tubes and the base together tubes were decanted. By this procedure hybrids bound to magnetic particles were retained in the tubes whereas the remaining unbound cDNAprobe was removed. Afterwards the tubes were washed with $1 \mathrm{ml}$ of washing solution $\left(60^{\circ} \mathrm{C}\right)$ and again, holding the tubes and the base together tubes were decanted. This procedure was repeated twice and tubes then counted in a gamma counter for $1 \mathrm{~min}$. The results are calculated based on the percentage of net counts added to each test tube.

\section{INVESTIGATING INTERFERENCE WITH OTHER MICROORGANISMS}

Urogenital isolates comprising the different microorganisms as listed in table 2 were cultured on Thayer Martin agar or Sabouraud agar, respectively, and colonies suspended in phosphate buffered saline (PBS). Mycoplasms were cultured in Shepard A7 medium. The various suspensions were centrifuged at $3000 \mathrm{~g}$ for $20 \mathrm{~min}$ and the pellet was resuspended and serially diluted on a $\log 10$ base using transport medium of the hybridisation assay. Fifty $\mu$ l of each of these suspensions were stored $1 \mathrm{~h}$ to release rRNA from the microorganisms and afterwards processed with the hybridisation assay. To determine the concentrations of the microorganisms aliquots of the suspensions diluted with PBS were plated on Thayer Martin agar without antibiotics or on Sabouraud agar, respectively, cultured and colonies were counted after 24 h. Mycoplasms were cultured on Shepard A7 agar and colonies were counted with a microscope after $72 \mathrm{~h}$.

\section{Results}

With the cell culture in 37 of 234 urogenital specimens $C$ trachomatis were isolated. This corresponds to an overall prevalence of chlamydial infections in the population investigated of $15 \cdot 8 \%$.

Thirty one of the 37 positive results obtained with the cell culture were confirmed with the hybridisation assay. Taking the cell culture results as the standard the hybridisation test had a sensitivity of $83.8 \%$ (table 1). In the cases in which the hybridisation test yielded discordent negative results less than five inclusions were found with the cell culture. Of the 197 specimens judged negative by cell culture only 186 were confirmed by the DNA hybridisation assay. In the 11 cases of discrepant results cell culture was repeated and passage performed once, without, however, yielding

Table 1 Comparison of a RNA:DNA hybridisation test and cell culture to detect Chlamydia trachomatis in urogenital specimens

\begin{tabular}{|c|c|c|c|c|}
\hline \multirow{2}{*}{$\begin{array}{l}\text { Cell culture detection } \\
\text { of inclusions by monoclonal } \\
\text { antibodies and immunofluorescence }\end{array}$} & \multicolumn{2}{|c|}{ RNA:DNA hybridisation with $a^{125}$ I-labelled probe } & \multirow[b]{2}{*}{ Sensitivity } & \multirow[b]{2}{*}{ Specificity } \\
\hline & Positive & Negative & & \\
\hline $\begin{array}{l}\text { Positive } \\
\text { Negative }\end{array}$ & $\begin{array}{l}31 \\
11\end{array}$ & $\begin{array}{r}6 \\
186\end{array}$ & $83.8 \%(31 / 37)$ & $94.4 \%(186 / 197)$ \\
\hline
\end{tabular}


Table 2 Interference of high amounts of microorganisms with the test procedure

\begin{tabular}{|c|c|}
\hline Species of microorganism & $\begin{array}{l}\text { First dilution step yielding } \\
\text { jalse-positive results in the } \\
\text { hybridisation test }\end{array}$ \\
\hline $\begin{array}{l}\text { Morganella morganii } \\
\text { Escherichia coli } \\
\text { Proteus mirabilis } \\
\text { Enterobacter species } \\
\text { Citrobacter diversus } \\
\text { Providentia stuartii } \\
\text { Klebsiella pneumoniae } \\
\text { Pseudomonas aeruginosa } \\
\text { Acinetobacter calcoaceticus } \\
\text { Neisseria gonorrhoeae } \\
\text { Streptococcus faecalis } \\
\text { Candida albicans } \\
\text { Torulopsis glabrata } \\
\text { Staphylococcus aureus } \\
\text { Staphylococcus epidermidis } \\
\text { Streptococcus group B } \\
\text { Ureaplasma urealyticum neg. up to } \\
\text { Mycoplasma hominis } \quad \text { neg. up to }\end{array}$ & $\begin{array}{l}6.2 \times 10^{8} \\
1.4 \times 10^{8} \\
5.5 \times 10^{8} \\
5.6 \times 10^{9} \\
2.5 \times 10^{7} \\
7.5 \times 10^{7} \\
2.5 \times 10^{8} \\
5.5 \times 10^{6} \\
9.7 \times 10^{8} \\
3.1 \times 10^{8} \\
4.6 \times 10^{8} \\
9.0 \times 10^{8} \\
5.0 \times 10^{7} \\
2.5 \times 10^{8} \\
9.2 \times 10^{7} \\
7.4 \times 10^{8} \\
2.0 \times 10^{7} \\
1.4 \times 10^{7}\end{array}$ \\
\hline
\end{tabular}

positive results. ${ }^{14}$ Accordingly the specificity of the hybridisation test reached $\mathbf{9 4 . 4 \%}$ (table 1). Predictive values for positive and negative results were $73.8 \%$ and $96.9 \%$, respectively.

To estimate whether microorganisms possibly present in the urogenital tract might interfere with the test procedure and cause false positive results transport medium enriched with different amounts of the microorganisms listed in table 2 was investigated with the hybridisation assay. With all microorganisms investigated at a final concentration in the range of 5.5 $\times 10^{6}$ to $9 \times 10^{8}$ per $50 \mu \mathrm{l}$ of transport medium false positive results were obtained. With Ureaplasma urealyticum and Mycoplasma hominis negative results were obtained up to $2 \times 10^{7}$ and $1.4 \times 10^{7}$ per $50 \mu \mathrm{l}$ (table 2).

\section{Discussion}

Recent advances in DNA technology have made it possible to produce large quantities of nucleic acid probes with defined sequences and permit the use of DNA hybridisation technique in clinical diagnosis. The DNA hybridisation test evaluated for the detection of $C$ trachomatis in clinical specimens is easy to handle and shortens the time to detect chlamydial DNA by hybridisation to four hours. This study shows that DNA hybridisation can be used effectively to detect $C$ trachomatis directly in clinical specimens.

In comparison with the results obtained with cell culture the DNA-hybridisation assay in six specimens could not detect $C$ trachomatis. Since the specificity of the cell culture, the golden standard of chlamydia diagnosis, is generally regarded to be near $100 \%$, it has to be assumed that in cases of discrepant results actually the hybridisation assay and not cell culture failed in the diagnosis of $C$ trachomatis infections. The number of inclusions in the cell cultures inoculated with the specimens yielding discrepant negative results in the hybridisation test were less than five. This suggests that at lower copy numbers of chlamydial rRNA the detection level of the hybridisation assay may be reached.

There were 11 discordant positive results obtained with the DNA-hybridisation assay which could not be confirmed by cell culture. In these cases on the one hand cell culture may partially have failed, since cell culture, although it is generally considered the most sensitive method does not reach $100 \% .{ }^{15-17}$ Failures of the cell culture were, however, minimised in our study since for the detection of inclusions fluoresceinlabelled antibodies were used and in the cases the DNA-hybridisation assay yielded discordant positive results cell culture was repeated and passage performed once. Thus discordant positive results of the hybridisation assay may on the other hand comprise cases of actual false-positive results partially resulting for instance from the presence of other bacteria which may interfere with the test system.

As demonstrated in additional experiments false positive results can principally occur in the test evaluated owing to the presence of large numbers of other microorganisms in the specimens. Two explanations seem possible: nucleic acid sequences of other microorganisms crosshybridise with the DNA-probe or microorganisms interfere nonspecifically with the test procedure. Since the false positive results obtained in the additional experiments did not occur selectively with only certain genetically related species of microorganisms, crosshybridisation is very unlikely to be the cause of the false positive results. The finding that false positive results were observed with concentrations approximately within the same range, with all species of microorganisms argues rather for the second explanation. As a consequence, contamination of specimens with microorganisms during sampling for instance by touching the vaginal walls with the swab should be avoided.

The feature which makes the available antibodybased direct detection tests not fully satisfactory for the requirements of $C$ trachomatis diagnosis is their lower sensitivity in comparison with cell culture. This problem becomes particularly relevant when populations with a low prevalence of chlamydial infections are investigated. Given the relatively high prevalence of $15.8 \%$ in our population the predictive value of positive results was only $73.8 \%$ for the DNA hybridisation assay evaluated. This means that in populations with a low prevalence a positive result of the DNA hybridisation test is not more reliable than that of the antigen detection tests. In contrast, the predictive value for negative results of $96.9 \%$ at a prevalence of 
$15.8 \%$ seems to be acceptable, even if higher prevalence rates are taken into account.

Sensitivity and also in part the specificity of the hybridisation test evaluated corresponded to those previously found with hybridisation assays. ${ }^{119}$ In these studies, however, only small numbers of selected specimens were investigated ${ }^{182021}$ and laborious hybridisation methods like sandwich-hybridisation ${ }^{20}$ and spot-hybridisation ${ }^{21}$ assays were used and/or time of performance was too long ${ }^{18-21}$ to permit tests to be alternatives for antigen detection tests. In contrast, the hybridisation test evaluated was as rapid and easy to perform as antigen detection tests. There remains, however, one drawback of the hybridisation test in comparison with the direct specimen immunofluorescence test or enzyme-immunoassay: the radioactive label of the DNA-probe. This feature limits the use of this hybridisation test for laboratories which lack facilities to work with isotopes. Therefore only nucleic acid-probes with a non-radioactive stain, for instance as previously demonstrated for the detection of chlamydial inclusions in cell cultures ${ }^{22}$ would make hybridisation tests like the one we have evaluated actually competitive with the antigen detection tests. Very recently such a DNA hybridisation test with a luminescence-based detection procedure has been introduced and is currently being evaluated.

The skilful technical assistance of Mrs U Stahlheber is gratefully acknowledged. The authors thank Mrs B Bürgy for preparing the manuscript.

\section{References}

1 Schachter J, Grossman M. Chlamydial infections. Ann Rev Med 1981;32:45-61.

2 Holmes KK, Handsfield HH, Wang SP, et al. Etiology of nongonococcal urethritis. N Engl J Med 1975;292:1199-206.

3 Mösinger-Lundgren V, Petzoldt D, Näher H. Direktnachweis von Chlamydia trachomatis mit monoklonalen Antikörpern. Hautarzt 1986;37:325-8.

4 Nowinski RC, Tam MR, Goldstein LC, et al. Monoclonal antibodies for diagnosis of infectious diseases in humans. Science 1983;219:637-44.

5 Tam MR, Stamm WE, Handsfield HH, et al. Culture-independent diagnosis of Chlamydia trachomatis using monoclonal antibodies. $N$ Engl J Med 1984;310:1146-50.

6 Hawkins DA, Thomas BJ, Taylor-Robinson D. Rapid detection of Chlamydia trachomatis with monoclonal antibodies. Lancet 1984;ii:38.

7 Näher H, Petzoldt D. Evaluation of an enzyme immunoassay (Chlamydiazyme) and a direct immunofluorescence technique (Mikro Trak) for the detection of Chlamydia trachomatis antigen in urogenital specimens. European Journal of Sexually Transmitted Diseases 1986;3:217-22.

8 Stary A, Kopp W, Gebhart W, Söltz-Szöts J. Culture versus direct specimen test: comparative study of infections with Chlamydia trachomatis in Viennese prostitutes. Genitourin Med 1985; 61:258-60.

9 Jones MF, Smith TF, Houglum AJ, et al. Detection of Chlamydia trachomatis in genital specimens by the Chlamydiazyme test. J Clin Microbiol 1984;20:465-7.

10 Hambling MH, Kurtz JB. Preliminary evaluation of an enzyme immunoassay test for the detection of Chlamydia trachomatis. Lancet 1985; i:53.

11 Schachter J. Rapid diagnosis of sexually transmitted diseasesspeed has a price. Diagn Microbiol Infect Dis 1986;4:185-9.

12 Pollice M, Yang HL. Use of nonradioactive DNA probes for the detection of infectious bacteria. Clin Lab Med 1985;5:463-73.

13 Horn JE, Quinn T, Hammer M, et al. Use of nucleic acid probes for the detection of sexually transmitted infectious agents. Diagn Microbiol Infect Dis 1986;4:101-9.

14 Schachter J, Martin DH. Failure of multiple passages to increase chlamydial recovery. J Clin Microbiol 1987;25:1851-3.

15 Wentworth BB. Sensitivity of cell culture for isolation of Chlamydia trachomatis from genital sources. In: Hobson D, Holmes KK, (eds). Nongonococcal urethritis and related infection. Am Soc Microbiol 1977;1877:299-303.

16 Ripa KT. Microbiological diagnosis of Chlamydia trachomatis infection. Infection 1982;10(suppl 1):19-23.

17 Embil JA, Tiebaux HJ, Manuel R, et al. Sequential cervical specimens and the isolation of Chlamydia trachomatis: factors affecting detection. Sex Trans Dis 1983;10:62-6.

18 Horn JE, Hammer ML, Falkow S, Quinn TC. Detection of Chlamydia trachomatis in tissue culture and cervical scrapings by in situ DNA hybridization. J Infect Dis 1986;153:1155-9.

19 Pao CC, Lin SS, Yang TE, et al. Deoxyribonucleic acid hybridization analysis for the detection of urogenital Chlamydia trachomatis infections in women. Am J Obstet Gynecol 1987; 156:195-9.

20 Palva A, Jousimies-Somer H, Saikku P, et al. Detection of Chlamydia trachomatis by nucleic acid sandwich hybridization. FEMS Microbiology Letters 1984;23:83-9.

21 Hyypiä T, Jalava A, Larsen SH, et al. Detection of Chlamydia trachomatis in clinical specimens by nucleic acid spot hybridization. J Gen Microbiol 1985;131:975-8.

22 Näher H, Petzoldt D, Sethi KK. Evaluation of non-radioactive in situ hybridisation method to detect Chlamydia trachomatis in cell culture. Genitourin Med 1988;64:162-4. 